\title{
Whole-body magnetic resonance imaging of Li-Fraumeni syndrome patients: observations from a two rounds screening of Brazilian patients
}

Daniele Paixão ${ }^{* *}$, Marcos Duarte Guimarães², Kelvin César de Andrade ${ }^{3,4}$, Amanda França Nóbrega', Rubens Chojniak ${ }^{2}$ and Maria Isabel Achatz ${ }^{5}$

\begin{abstract}
Background: Li-Fraumeni syndrome (LFS) is an autosomal dominant disease that is associated with germline TP53 mutations and it predisposes affected individuals to a high risk of developing multiple tumors. In Brazil, LFS is characterized by a different pattern of TP53 variants, with the founder TP53 p.R337H mutation being predominant. The adoption of screening strategies to diagnose LFS in its early stages is a major challenge due to the diverse spectrum of tumors that LFS patients can develop. The purpose of this study was to evaluate two rounds of whole-body magnetic resonance imaging (WB-MRI) which were conducted as a screening strategy for LFS patients.

Methods: Over a 4-year period, 59 LFS patients underwent two rounds of WB-MRI. Each MRI was characterized as positive or negative, and positive cases were further investigated to establish a diagnosis. The parameters used to evaluate the WB-MRI results included: positive rate, number of invasive investigations of positive results, and cancer detection rate.
\end{abstract}

Results: A total of 118 WB-MRI scans were performed. Positive results were associated with 11 patients (9.3\%). Seven of these patients (11.8\%) were identified in the first round of screening and 4 patients (6.7\%) were identified in the second round of screening. Biopsies were performed in three cases (2.5\%), two (3.4\%) after the first round of screening and one (1.7\%) after the second round of screening. The histopathological results confirmed a diagnosis of cancer for all three cases. There was no indication of unnecessary invasive procedures.

Conclusions: WB-MRI screening of LFS carriers diagnosed cancers in their early stages. When needed, positive results were further examined with non-invasive imaging techniques. False positive results were less frequent after the first round of WB-MRI screening.

Keywords: Li-Fraumeni syndrome, Whole-body MRI, Cancer screening, TP53, p.R337H mutation

\section{Background}

Li-Fraumeni syndrome (LFS) is a hereditary cancer predisposition syndrome that is associated with germline TP53 mutations [1]. Those affected by this syndrome are at high risk of developing multiple tumors, both as children and as young adults. The spectrum of tumors that characterize LFS include premenopausal breast cancer,

\footnotetext{
* Correspondence: danipaixaop@gmail.com

${ }^{1}$ Department of Oncogenetics, A.C. Camargo Cancer Center, Professor Antonio Prudente Street, 211 - Liberdade, São Paulo, SP 01509-900, Brazil Full list of author information is available at the end of the article
}

soft tissue sarcoma, osteosarcoma, adrenocortical carcinoma, and brain tumors [2-5]. However, other tumors associated with LFS have been reported as well, including leukemia, Wilms' tumor, lung, stomach, colorectal, pancreatic, prostate, and choroid plexus carcinomas [6-9].

In Brazil, there is a high prevalence of LFS due to a founder effect [10]. A germline arginine-to-histidine substitution at codon 337 (NC_000017.9: c.1010G > A; p.R337H) is present in $0.3 \%$ in the South/Southeastern Brazilian regions. It is estimated that penetrance of LFS associated with the p.R337H mutation is lower than that

(c) The Author(s). 2018 Open Access This article is distributed under the terms of the Creative Commons Attribution 4.0 International License (http://creativecommons.org/licenses/by/4.0/), which permits unrestricted use, distribution, and 
of other germline TP53 mutations, with a cumulative lifetime risk of 50 to $60 \%$ [10-13].

Effective screening strategies for LFS patients represent a major challenge due to the wide spectrum of tumors and their variable ages at onset that characterize this syndrome. Previous studies have evaluated the use of ${ }^{18} \mathrm{~F}$-fluorodeoxyglucose positron emission tomography/computed tomography $\left({ }^{18} \mathrm{~F}\right.$-FDG-PET/CT) as a screening tool for LFS patients $[14,15]$. However, since impaired p53 function may enhance the risk of radiation-induced primary tumors in these subjects, the use of this and other radiation-based imaging modalities is not recommended [16-18].

Whole-body magnetic resonance imaging (WB-MRI) is widely used in oncology and it has been proposed as a surveillance strategy for LFS patients [19-24]. This imaging method involves the acquisition of images of the entire body in one or more planes by using fast sequences, and high sensitivity and specificity have been reported for this method in the detection of a wide variety of malignant tumors [20-24]. For example, in a study by Villani et al. [19], a tumor surveillance protocol for both adult and children affected by LFS was proposed which included the use of WB-MRI for cancer screening. A total of 18 LFS patients carrying a TP53 mutation were monitored for six years. Five malignant tumors were diagnosed in 7 out of 18 patients, including two choroid plexus carcinomas, two adrenocortical carcinomas, and one sarcoma. All of the tumors were diagnosed in asymptomatic patients and a $100 \%$ survival rate was reported at the end of the study. In comparison, the survival rate for patients who did not undergo surveillance during the same time period was $23 \%$. These significant results led the National Comprehensive Cancer Network to propose that WB-MRI be included in its guidelines for the management and risk reduction of cancer in children and adults who harbor a TP53 germline mutation [25].

In another study of WB-MRI conducted by Anupindi et al. [26], 24 children with cancer predisposition conditions, including LFS, paraganglioma-pheochomocytoma syndrome, and rhabdoid tumor syndrome, underwent a total of 50 WB-MRI screenings over five years. Abnormal findings were detected in $18 \%$ of the patients examined. Among these findings, a papillary thyroid carcinoma was confirmed to carry a TP53 mutation. Thus, in this study, WB-MRI had $100 \%$ sensitivity and $94 \%$ specificity [26].

In 2017, Ballinger et al. [27] conducted a meta-analysis to estimate the performance and frequency of cancer detection by WB-MRI. A total of 578 patients with deleterious germline TP53 mutations from 13 participating cohorts in six countries were coordinated through the Li-Fraumeni Exploration Research Consortium. Baseline WB-MRI screenings detected 225 lesions in 173 patients. Forty-two malignant neoplasms were identified in 39 individuals, and most of the them were early-stage neoplasms. The resulting cancer detection rate was $7 \%$, although the false-positive rate was $43 \%$. The false-negative rate was not estimated [27].

In 2017, Mai et al. [28] also evaluated a screening protocol that included WB-MRI for examining $116 \mathrm{pa}-$ tients of a National Cancer Institute (NCI) Li-Fraumeni cohort. In this baseline screening, cancers were detected in $6.9 \%$ of the cohort, and $34.5 \%$ of these lesions required further investigation. The false-positive rate was $29.6 \%$.

Asdahl et al. [29] has cautioned against false positive results and cancer overdiagnosis in LFS screenings which may lead to psychological distress and unnecessary invasive procedures. However, for individuals with LFS, there is sufficient evidence to indicate that the benefits of screening outweighs its risks.

Considering this unique population that has a high frequency of LFS patients, the aim of this study was to evaluate the use of WB-MRI for early tumor detection in Brazilian LFS patients. Two rounds of WB-MRI screenings were performed and various radiological parameters were examined to evaluate this screening approach.

\section{Methods \\ Patients}

Between January 2013 and August 2017, LFS patients were recruited for this study from those undergoing follow-up in the Department of Oncogenetics at the A.C. Camargo Cancer Center (São Paulo, Brazil). It was confirmed that the enrolled patients carried a pathogenic germline mutation in the TP53 gene. A subset of the enrolled patients had a previous history of cancer, yet none of the enrolled patients had evidence of current disease. Patients with a current malignancy or metastatic cancer, pregnant or lactating patients, patients who had surgery or received chemotherapy within the previous four months, and patients who refused to participate in the study were excluded.

\section{Ethical issues}

All patients signed a written informed consent after completing a consultation with a genetic counselor. This study was approved by the local Ethics Committee of the A.C. Camargo Cancer Center (protocol number 1832/13).

\section{WB-MRI}

WB-MRI was performed for 59 LFS patients over a 55 -month period in the Nuclear Medicine Division of the Imaging Department, A.C. Camargo Cancer Center. Image acquisition included spin echo and turbo spin echo techniques with coverage tip to toe. Coronal T1-weighted images, short TI inversion recovery (STIR) images, and axial diffusion-weighted images were collected. A 1.5 T MRI 
instrument (Signa Excite HD; GE Healthcare, Milwaukee, WI, USA) with a quadrature body coil and maximum power gradient of $33 \mathrm{mT} / \mathrm{m}$ and a pulse rate of $160 \mathrm{mT} /$ $\mathrm{m} / \mathrm{s}$ was used. Paramagnetic contrast reagent was not administered in any of the cases. The WB-MRI scanning time was $25-35 \mathrm{~min}$. All images were interpreted by experienced radiologists using an Advantage Windows version 4.2-07 workstation (GE Healthcare). Functool (GE Healthcare) was used to analyze diffusion sequences.

The WB-MRI results were characterized as: (1) positive: defined as suspicious findings of malignancy or undetermined lesions present; or (2) negative: defined as probable benign lesions or an absence of lesions. Patients with positive WB-MRI results were referred to a specialist for clinical management and further follow-up imaging. We evaluated if there was indication of unnecessary invasive procedures in patients with positive results, i.e., biopsy or surgery performed with unconfirmed histopathological result of cancer.

\section{Radiological parameters}

The following radiological parameters were used to evaluate and interpret the WB-MRI results: (1) success rate was measured based on the number of exams performed without complication and without sedation/anesthesia; (2) positive rate was measured according to the number of positive WB-MRI results; (3) recall rate was measured based on the number of patients requiring further investigation after WB-MRI; and (4) cancer detection rate was measured based on the number of malignancies diagnosed by WB-MRI.

\section{Results}

A total of 118 WB-MRI scans were performed for 59 LFS patients ( 35 females, 24 males) from 23 families with a mean age of 38 years (range: $2-71$ ) at the time of their initial WB-MRI examination. Among these patients, 50 (85\%) carried the founder mutation, p.R337H, and 9 (15\%) carried other germline TP53 mutations. A total of 27 (45\%) patients had a prior history of cancer, with 12 previously receiving a diagnosis of multiple primary tumors (Additional file 1: Table S1). A second WB-MRI was performed for all of the patients after a minimum interval of 12 months.

The initial round of WB-MRI had a low positivity rate (11.8\%), a low recall rate (11.8\%), few invasive investigations
(3.4\%), and a cancer detection rate of 3.4\% (Table 1). The success rate for the execution of the initial WB-MRI screenings was high (95\%). Only two pediatric patients and one adult patient who was claustrophobic required sedation. Positive results were obtained for seven patients, and further investigations with other imaging exams were performed to rule out suspected malignant lesions (Table 2). Two of these patients required biopsy and the histopathologic findings confirmed a diagnosis of cancer in both patients.

One of the positive patients was a 19-year-old female carrier of p.R337H (Y0102T000) with a previous history of multiple primary tumors. Her initial WB-MRI detected bilateral renal cortical alterations. An abdominal MRI further detected an enhanced solid lesion in the right kidney (Fig. 1a and b). Pathological findings confirmed papillary renal cell carcinoma (T1AN0M0, stage I). The second positive patient was a 29-year-old female carrier of p.R306X (Y0352T000). She was asymptomatic and had no previous history of cancer. Her initial WB-MRI screening detected a nodule in the left sacroiliac joint (Fig. 2a and b). A pelvic MRI further showed an enhanced solid expansive lesion present (Fig. 2c). Pathological findings confirmed the lesion to be grade 1 chondrosarcoma.

The positive rate and recall rate for the second round of WB-MRI screenings for all 59 patients were both $6.7 \%$. The success rate was $100 \%$ and sedation/anesthesia was not needed for any of the screenings (Table 1). Four positive results were detected and further examinations were performed (Table 2). A biopsy was only performed for one patient and the histopathological results confirmed cancer. Meanwhile, the remaining three patients had their suspected lesions ruled as benign. Overall, the cancer detection rate for the second round of WB-MRI examinations was $1.7 \%$, which is lower than the cancer rate in the first round of WB-MRI screenings. In addition, there was a lower indication of further investigation in the second round of WB-MRI examinations.

The confirmed positive finding in the second round of WB-MRI screenings involved a 61-year-old asymptomatic male carrier of p.R337H (Y0012T012) with a previous history of a thyroid cancer at the age of 54 . An expansive lesion was detected in the proximal segment of the right humerus that was in contact with the short head of the biceps (Fig. 3a and b). This

Table 1 Summary of WB-MRI results according to various radiological parameters

\begin{tabular}{llll}
\hline Radiological parameters & $\begin{array}{l}1^{\text {st }} \text { WB-MRI, } n=59 \\
\%(n)\end{array}$ & $\begin{array}{l}2^{\text {st }} \text { WB-MRI, } n=59 \\
\%(n)\end{array}$ & $\begin{array}{l}\text { Total, } n=118 \\
\%(n)\end{array}$ \\
\hline Positivity rate & $11.8(7)$ & $6.7(4)$ & $9.3(11)$ \\
Recall rate & $11.8(7)$ & $6.7(4)$ & $9.3(11)$ \\
Cancer detection rate & $3.4(2)$ & $1.7(1)$ & $2.5(3)$ \\
Success rate & $95.0(56)$ & $100.0(59)$ & $98.0(116)$ \\
\hline
\end{tabular}


Table 2 Further investigation of the positive cases identified in the first and second-round of WB-MRI screenings

\begin{tabular}{|c|c|c|c|c|c|c|c|c|}
\hline $\begin{array}{l}\text { Patient ID } \\
\text { no. }\end{array}$ & $M / F$ & $\begin{array}{l}\text { Age } \\
\text { (y) }\end{array}$ & $\begin{array}{l}\text { TP53 } \\
\text { mutation }\end{array}$ & WB-MRI findings & $\begin{array}{l}\text { Further } \\
\text { exams }\end{array}$ & $\begin{array}{l}\text { Imaging } \\
\text { diagnosis }\end{array}$ & $\begin{array}{l}\text { Invasive } \\
\text { exams }\end{array}$ & $\begin{array}{l}\text { Cancer } \\
\text { diagnosis }\end{array}$ \\
\hline Y0012T044 & $\mathrm{F}$ & 40 & p.R337H & $\begin{array}{l}\text { Hyposignal area on T1, high } \\
\text { signal focuses on STIR in left } \\
\text { humeral head, nonspecific aspect. }\end{array}$ & Shoulder MRI & Vascular ectasia & No & No \\
\hline Y0012T049 & $\mathrm{F}$ & 61 & p.R337H & $\begin{array}{l}\text { Rounded image in distal } \\
\text { metaphyseal region of the right } \\
\text { femur }(2.2 \mathrm{~cm}) \text { with hyposignal } \\
\text { on T1 and hypersignal on STIR. }\end{array}$ & Leg MRI & $\begin{array}{l}\text { Lobulated image in right } \\
\text { femur compatible with } \\
\text { enchondroma }\end{array}$ & No & No \\
\hline Y0079T016 & $\mathrm{F}$ & 41 & p.T125T & $\begin{array}{l}\text { Sacral nodule }(20 \mathrm{~mm}) \text {, } \\
\text { nonspecific, }\end{array}$ & $\begin{array}{l}\text { Lumbosacral } \\
\text { spine CT }\end{array}$ & Enostoses & No & No \\
\hline Y0099T001 & $\mathrm{F}$ & 34 & p.R337H & $\begin{array}{l}\text { Nodular area }(17 \mathrm{~mm}) \text { in the } \\
\text { retroperitoneum, adjacent to } \\
\text { pancreatic cephalic region. }\end{array}$ & $\begin{array}{l}\text { Abdominal } \\
\text { MRI }\end{array}$ & Unilocular pancreatic cyst & No & No \\
\hline Y0102T000 & $\mathrm{F}$ & 17 & p.R337H & $\begin{array}{l}\text { Oval images in renal cortical, } \\
16 \mathrm{~mm} \text { in the lower pole of the } \\
\text { right kidney and } 20 \mathrm{~mm} \text { in the } \\
\text { upper pole of the left kidney. }\end{array}$ & $\begin{array}{l}\text { Abdominal/ } \\
\text { Pelvis MRI }\end{array}$ & $\begin{array}{l}\text { Nodule with irregular borders } \\
\text { and heterogeneous signal, } \\
\text { predominantly high in T1 } \\
\text { and intermediate in } T 2 \text {, with } \\
\text { restrictions on diffusion sequence. } \\
\text { Approximately, } 23 \times 18 \times 18 \mathrm{~mm}^{3} \\
\text { in right kidney }\end{array}$ & $\begin{array}{l}\text { Surgical } \\
\text { resection }\end{array}$ & $\begin{array}{l}\text { Renal cell } \\
\text { carcinoma }\end{array}$ \\
\hline Y0183Т001 & M & 19 & p.T125T & $\begin{array}{l}\text { Image on the left lenticular } \\
\text { nucleus, } 8 \mathrm{~mm} \text {. }\end{array}$ & Brain MRI & $\begin{array}{l}\text { Cystic image in the left putamen, } \\
\text { compatible with Virchow-Robin } \\
\text { space }\end{array}$ & No & No \\
\hline Y0352T000 & $\mathrm{F}$ & 29 & p.R306X & $\begin{array}{l}\text { Nodule } 35 \times 28 \mathrm{~mm}^{2} \text { at the } \\
\text { left sacroiliac joint. }\end{array}$ & Pelvis MRI & $\begin{array}{l}\text { Solid mass lesion } 43 \times 34 \times \\
30 \mathrm{~mm}^{3} \text {, located in the } \\
\text { posterior-inferior region of } \\
\text { the left sacroiliac joint, with } \\
\text { bone cortical irregularity in } \\
\text { the sacral margin }\end{array}$ & $\begin{array}{l}\text { Surgical } \\
\text { resection }\end{array}$ & $\begin{array}{l}\text { Grade } 1 \\
\text { chondrosarcoma }\end{array}$ \\
\hline Y0102T000 & $\mathrm{F}$ & 18 & p.R337H & $\begin{array}{l}\text { Nodule in the right adrenal } \\
\text { gland with hypointense signal } \\
\text { on T1, hyperintense signal on } \\
\text { STIR, and diffusion sequence. } \\
\text { Measures } 15 \mathrm{~mm} \text {, indeterminate } \\
\text { aspect. }\end{array}$ & $\begin{array}{l}\text { Abdominal } \\
\text { MRI }\end{array}$ & $\begin{array}{l}\text { Nodule in the right adrenal } \\
\text { gland, non-aggressive features }\end{array}$ & No & No \\
\hline Y0015T011 & M & 34 & p.R337H & $\begin{array}{l}\text { Images in humeral heads with } \\
\text { hypointense signal on T1 and } \\
\text { hyperintense signal on STIR, } \\
\text { measuring up to } 9 \mathrm{~mm} \text {, } \\
\text { suggestive of subchondral cysts. }\end{array}$ & $\begin{array}{l}\text { Shoulder } \\
\text { MRI, CT and } \\
\text { scintigraphy }\end{array}$ & $\begin{array}{l}\text { Radiolucent oval image in } \\
\text { the scapular region with } \\
\text { non-aggressive features, slight } \\
\text { increase in bone metabolism, } \\
\text { no change in blood flow, } \\
\text { suggestive of cystic lesion or } \\
\text { enchondroma }\end{array}$ & No & No \\
\hline Y0012T012 & M & 61 & p. R337H & $\begin{array}{l}\text { Expansive lesion in the right } \\
\text { humerus, measuring } 48 \times 34 \mathrm{~mm}^{2} \text {, } \\
\text { with isosignal to muscle on } \mathrm{T1} \text {, } \\
\text { hyperintense signal on } \mathrm{STIR} \text {, and } \\
\text { restriction on diffusion sequence. }\end{array}$ & Shoulder MRI & $\begin{array}{l}\text { Expansive lesion in the right } \\
\text { axillary region, next to the } \\
\text { distal roots of the brachial } \\
\text { plexus, measuring } 32 \times 22 \mathrm{~mm}^{2} \text {, } \\
\text { with hypointense signal on T1, } \\
\text { hyperintense signal on STIR, } \\
\text { suggestive of malignancy of } \\
\text { neural sheath or soft tissue } \\
\text { sarcoma }\end{array}$ & $\begin{array}{l}\text { Biopsy } \\
\text { (axilar } \\
\text { lymph } \\
\text { node) }\end{array}$ & $\begin{array}{l}\text { High-grade } \\
\text { sarcoma with } \\
\text { muscle } \\
\text { differen- tiation }\end{array}$ \\
\hline Y0171T005 & M & 47 & p. R337H & $\begin{array}{l}\text { Subcutaneous nodule on the } \\
\text { left shoulder. }\end{array}$ & $\begin{array}{l}\text { Shoulder } \\
\text { ultrasound }\end{array}$ & $\begin{array}{l}\text { Echogenic nodule in the } \\
\text { subcutaneous tissue of the } \\
\text { left shoulder, measuring } \\
65 \times 57 \times 12 \mathrm{~mm}^{3} \text {, characteristics } \\
\text { of lipoma }\end{array}$ & No & No \\
\hline
\end{tabular}

finding suggested a malignancy of the neural sheath or a soft tissue sarcoma. Pathology subsequently confirmed the presence of a high-grade sarcoma with muscle differentiation.

\section{Discussion}

The adoption of a screening strategy for the early detection of tumors in LFS patients remains a challenge due to the wide spectrum of tumors that can develop. 


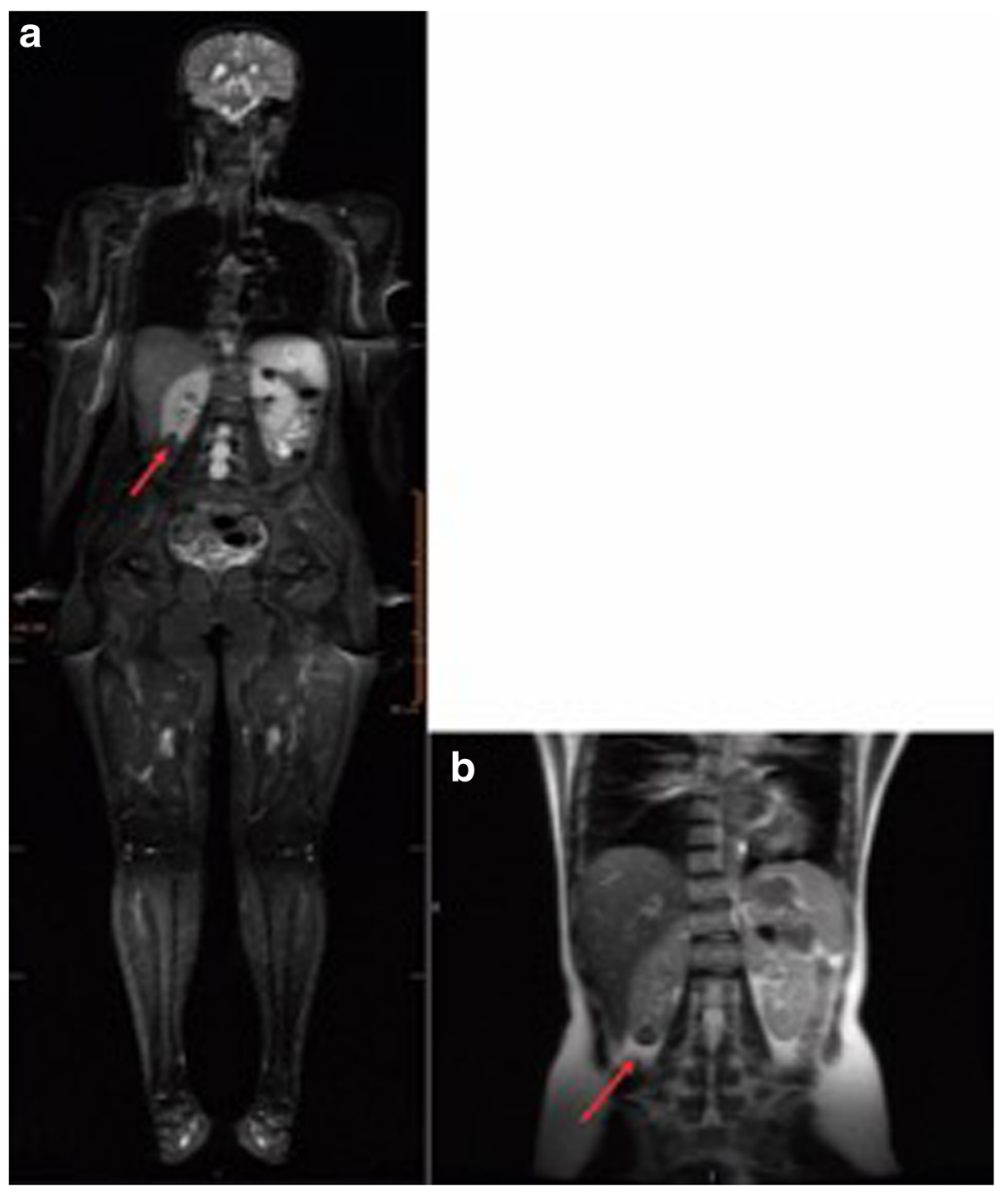

Fig. 1 Detection of a renal lesion by WB-MRI in LFS patient, Y0102T000. a STIR image of a 19-year-old with cortical oval kidney lesions in the right lower pole $(16 \mathrm{~mm})$ and in the left upper pole $(20 \mathrm{~mm})$ (indicated with arrows). b An abdominal MRI detected a complex nodule in the lower third of the right kidney, and it measured $23 \times 18 \times 18 \mathrm{~mm}^{3}$ (indicated with an arrow)

However, recent studies have shown that WB-MRI can be effective for the screening of patients with cancer predisposition syndromes, including LFS [19, 26].

WB-MRI with diffusion-weighted imaging has the advantage that it is a noninvasive technique that does not require exposure to ionizing radiation or paramagnetic contrast reagent. This is particularly relevant for LFS patients who are advised to avoid exposure to ionizing radiation due to their higher risk of developing radiation-induced primary tumors [14, 16-18]. In the present study, 118 WB-MRI screenings were performed for 59 carriers of germline TP53 mutations. After two rounds of WB-MRI screenings, cancers were detected in two (4\%) out of 50 carriers of the founder mutation, p.R337H, and one cancer (11\%) was detected among 9 carriers of the other germline TP53 mutations. For the three positive cases, biopsies were necessary and the histopathological results confirmed malignant lesions in each case: renal cell carcinoma, grade 1 chondrosarcoma, and soft tissue sarcoma. There was no indication of unnecessary invasive procedures. All of the lesions were also detected in their early stages of development in asymptomatic individuals. Consequently, surgical resection was the primary treatment with no additional need for chemotherapy or radiation treatment. Thus, WB-MRI screening in the present cohort was characterized by a high success rate, minimal need for sedation, and good tolerance and acceptance of the screening protocol.

It is important to note that one of the three diagnosed cancers were detected during the second round of WB-MRI screenings that were performed 12 months after the initial WB-MRI screenings. This result supports the relevance of annual examinations for LFS patients. These results are also consistent with previous observations that WB-MRI facilitates the early detection of malignant tumors [19, 26-28]. Low positivity and recall rates were observed, and further investigations of positive results predominantly involved radiological methods. Only a small proportion of the patients examined underwent an invasive exam with biopsies performed to confirm malignant tumors.

High false-positive rates in screening protocols have been shown to increase the potential for excessive subsequent 


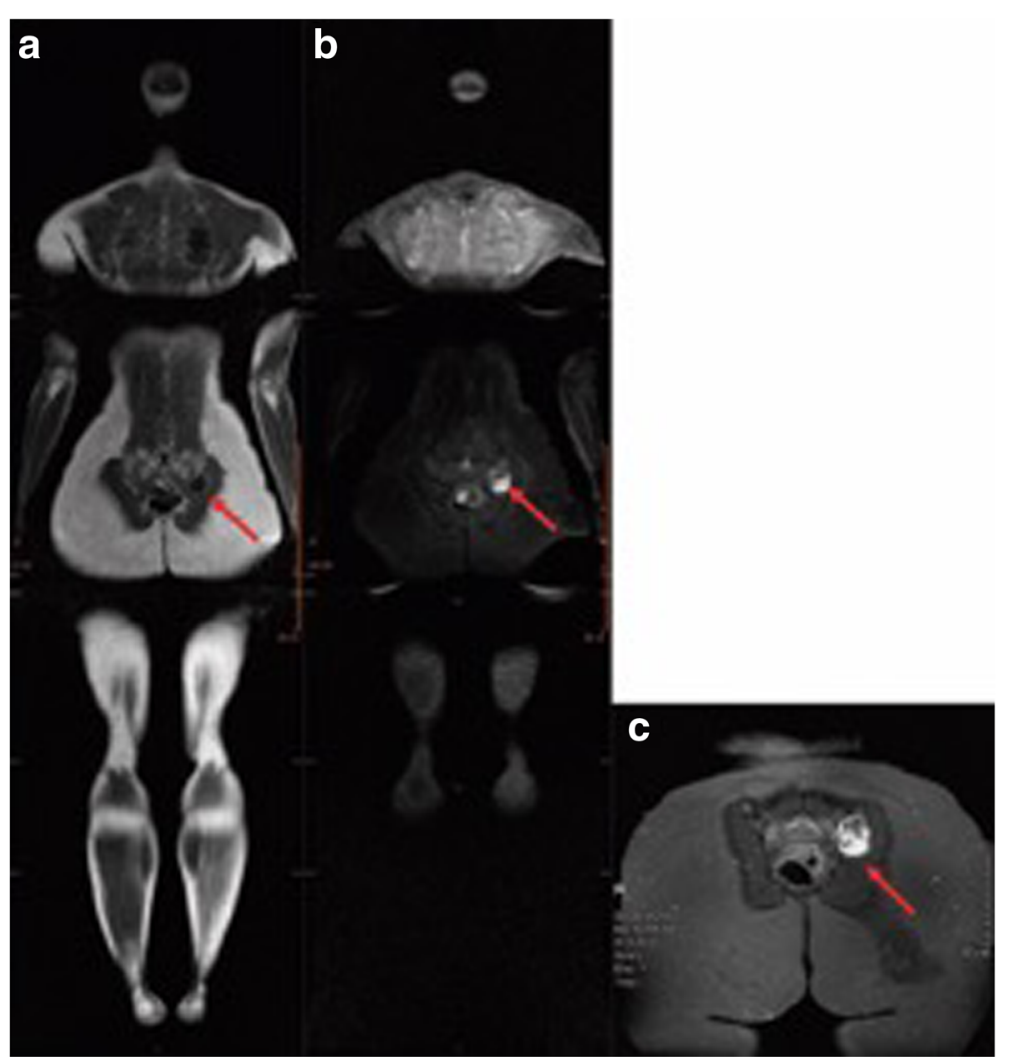

Fig. 2 Detection of a sacroiliac joint lesion by WB-MRI and pelvic MRI images of LFS patient, Y0352T000. A T1-weighted image (a) and a STIR image (b) were obtained with WB-MRI. c MRI of the sacroiliac region detected a solid expansive lesion in the posterior-inferior region of the left sacroiliac joint. Bone cortical irregularity was observed in the sacral margin and it was accompanied by bone edema (indicated with arrow)

investigations and unnecessary invasive procedures [29]. In the present study, a significantly lower positive rate was observed in the second round of WB-MRI screenings, thereby reducing the need for further investigations. This result was expected for a screening process and these data reinforce the findings of Ballinger et al. [27] that WB-MRI may be an integral part of a screening strategy for this high-risk population of patients.

It should be noted that there were limitations associated with the present study. For example, there was a high proportion of younger patients $(<40 \mathrm{y})$ included in the cohort examined, and the majority of the carriers examined harbored the p.R337H mutation. The latter has been characterized as having a reduced penetrance at younger ages compared to other classic mutations associated with LFS patients [10-13]. Among the 50 patients who carried the p.R337H mutation, the cancer detection rate was low. For example, it has been reported that approximately $15 \%$ of individuals carrying p.R337H develop cancer by the age of 30 , whereas patients who carry other mutations in the TP53 gene present a risk of $50 \%$ up to the age of 35 years $[5,10,30]$. These observations may account for the low rate of cancer detection that was observed in the present study.

Another limitation of the present study was that the WB-MRI results were not compared with other imaging modalities. However, to date, there is no gold standard that has been established for cancer screenings of LFS patients. Thus, it is not possible to evaluate the effectiveness of the exams performed.

A major challenge in the screening of LFS patients is the management of pediatric cases. A protocol proposed by Villani et al. [19] indicates specific tests for children with LFS, particularly for the detection of adrenocortical carcinomas, brain tumors, and hematological cancers, and the protocol recommends performing WB-MRI annually to detect sarcomas. There is still no consensus regarding the best age at which to start WB-MRI screenings, and its application to young children is challenging due to the need for sedation or general anesthesia, neither of which are without risks. Anupindi et al. [26] reported that $58 \%$ of pediatric patients required sedation for WB-MRI screenings, and complications from the procedure were documented in six patients. In the present study, use of sedation was necessary in two 


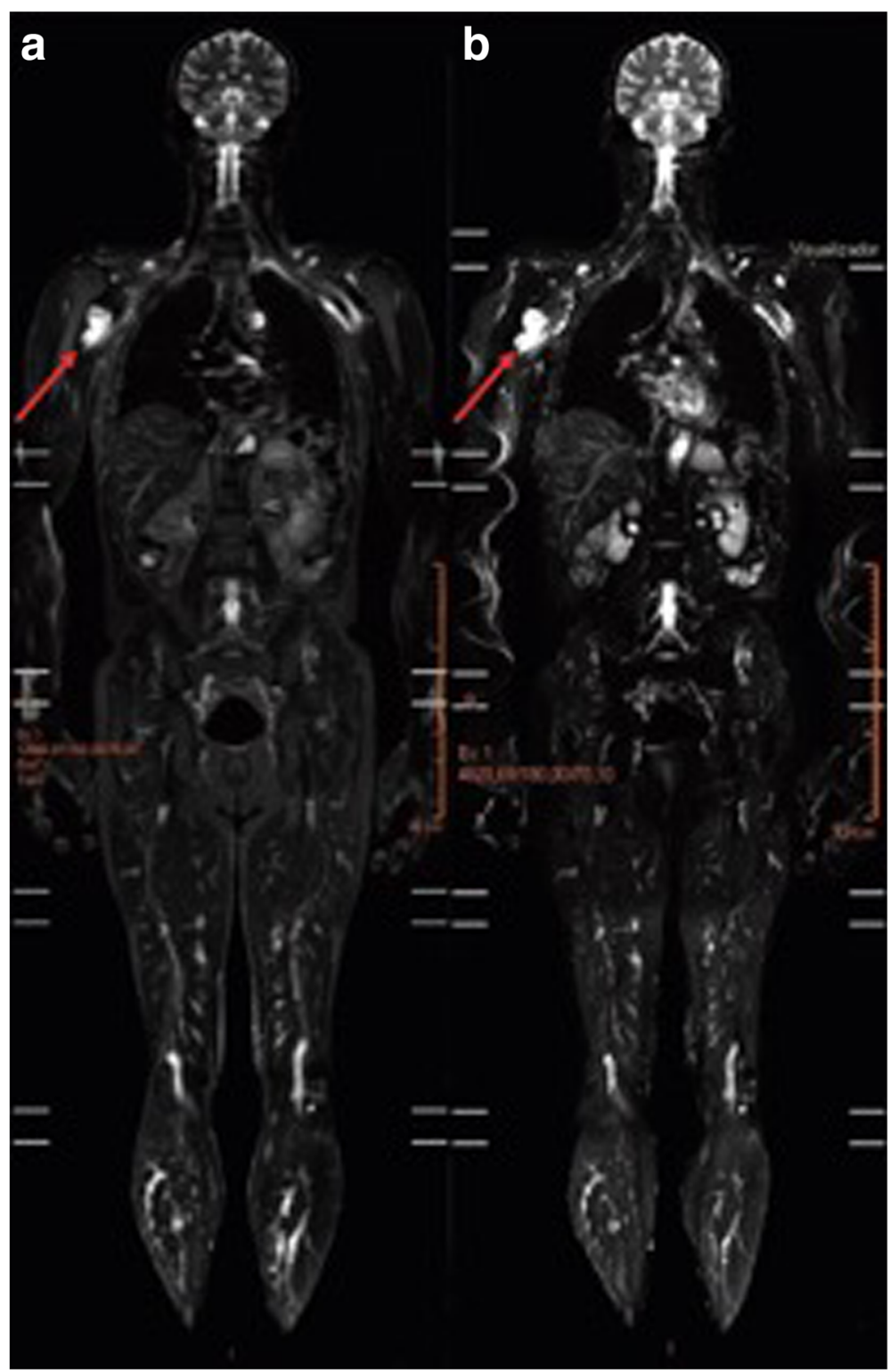

Fig. 3 WB-MRI of LFS patient, Y0012T012. A STIR image (a) and diffusion-weighted imaging (b) from WB-MRI. An expansive lesion (48 $\times 34 \mathrm{~mm}^{2}$ ) in contact with the short head of the biceps was detected in the proximal segment of the right humerus. The lesion exhibited a hyperintense signal on STIR and restriction on diffusion-weighted imaging scans (indicated with arrows)

pediatric cases involving a 2-year-old and a 3-year-old, and no further complications were observed. Thus, sedation for WB-MRI has generally been observed to be a safe procedure. However, the risk-benefit of WB-MRI with sedation/general anesthesia for children remains to be confirmed with further studies.

\section{Conclusion}

Despite the limitations associated with this study, a large cohort of LFS patients were evaluated with two rounds of WB-MRI screenings, including a large proportion of Brazilian LFS patients carrying the p.R337H mutation. Our results indicate that cancer screening based on WB-MRI facilitated the early detection of malignant neoplasms and it was characterized by lower recall rates and fewer follow-up invasive investigations. Furthermore, in the second round of screening, fewer positive results were observed. Therefore, we recommend that WB-MRI should be performed as a complementary method to other proposed tests for the surveillance of LFS patients, although longitudinal studies are still needed to better evaluate the effectiveness and long-term impact of WB-MRI on the survival of LFS patients. 


\section{Additional file}

Additional file 1: Table S1. Characteristics of the LFS patients screened in this study. Clinical details and germline TP53 mutations of the LFS patients examined. Reference sequences used for annotating TP53 mutations included: NC_000017.9 (NCBI36/hg18, Chr17:7512445..7531642), NM_000546.4, and UniProt P04637 from GenBank). Mutations are presented according to HGVS nomenclature. Abbreviations: F, female; $M$, male; ADR, adrenocortical carcinoma; STS, soft tissue sarcoma; CNS, central nervous system. (DOCX $15 \mathrm{~kb})$

\section{Abbreviations}

18F-FDG-PET/CT: 18F-fluorodeoxyglucose positron emission tomography/ computed tomography; LFS: Li-Fraumeni syndrome; NCl: National Cancer Institute; STIR: Short TI inversion recovery; WB-MRI: Whole-body magnetic resonance imaging

\section{Acknowledgements}

We would like to acknowledge the LFS patients who participated in this study.

\section{Funding}

This research did not receive any specific grant from funding agencies in the public, commercial, or not-for-profit sectors.

\section{Availability of data and materials}

The datasets analysed during the current study available from the corresponding author on reasonable request.

\section{Authors' contributions}

RC, MIA, and DP designed the study. RC and MIA supervised the research. DP and MIA actively participated in genetic counseling consultations. DP acquired clinical data, with collaboration from AFN. RC and MDG analyzed the WB-MRI results. MDG and DP selected the WB-MRI images presented in this manuscript. RC, DP and MIA interpreted and discussed the results. DP, RC, MIA, and KCA wrote the manuscript. All of the authors approved and contributed to the final version of the manuscript.

\section{Ethics approval and consent to participate}

This project received approval from the institution's Research Ethics Committee (1832/13).

\section{Consent for publication}

Not applicable.

\section{Competing interests}

The authors declare that they have no competing interest.

\section{Publisher's Note}

Springer Nature remains neutral with regard to jurisdictional claims in published maps and institutional affiliations.

\begin{abstract}
Author details
${ }^{1}$ Department of Oncogenetics, A.C. Camargo Cancer Center, Professor Antonio Prudente Street, 211 - Liberdade, São Paulo, SP 01509-900, Brazil. 2Department of Imaging, A.C. Camargo Cancer Center, São Paulo, SP, Brazil. ${ }^{3}$ Clinical Genetics Branch, Division of Epidemiology and Cancer Genetics, National Cancer Institutes, National Institutes of Health, Bethesda, MD, USA. ${ }^{4}$ International Research Center, A.C. Camargo Cancer Center, São Paulo, SP, Brazil. ${ }^{5}$ Centro de Oncologia, Hospital Sírio-Libanês, São Paulo, Brazil.
\end{abstract}

Received: 29 June 2018 Accepted: 2 August 2018 Published online: 14 August 2018

\section{References}

1. Merino D, Malkin D. p53 and hereditary cancer. Subcell Biochem. 2014; 85:1-16.

2. Li FP, Fraumeni JF Jr, Mulvihill JJ, et al. A cancer family syndrome in twentyfour kindreds. Cancer Res. 1988;48:5358-62.
3. Malkin D, Li FP, Strong LC, et al. Germline p53 mutations in a familial syndrome of breast cancer, sarcomas, and other neoplasms. Science. 1990;250:1233-8.

4. Srivastava S, Zou ZQ, Pirollo K, et al. Germ-line transmission of a mutated p53 gene in a cancer-prone family with li-Fraumeni syndrome. Nature. 1990;348:747-9.

5. Hisada M, Garber JE, Fung CY, et al. Multiple primary cancers in families with li-Fraumeni syndrome. J Natl Cancer Inst. 1998;90:606-11.

6. Hartley AL, Birch JM, Kelsey AM, et al. Are germ cell tumors part of the liFraumeni cancer family syndrome? Cancer Genet Cytogenet. 1989:42:221-6.

7. Garber JE, Burke EM, Lavally BL, et al. Choroid plexus tumors in the breast cancer-sarcoma syndrome. Cancer. 1990;66:2658-60.

8. Hartley AL, Birch JM, Tricker K, et al. Wilms' tumor in the Li-Fraumeni cancer family syndrome. Cancer Genet Cytogenet. 1993;67:133-5.

9. Varley JM, Evans DG, Birch JM. Li-Fraumeni syndrome - a molecular and clinical review. Br J Cancer. 1997;76:1-14.

10. Garritano S, Gemignani F, Palmero El, et al. Detailed haplotype analysis at the TP53 locus in P.R337H mutation carriers in the population of Southern Brazil: evidence for a founder effect. Hum Mutat. 2010;31:143-50.

11. Achatz MI, Olivier M, Le Calvez F, et al. The TP53 mutation, R337H, is associated with li-Fraumeni and li-Fraumeni-like syndromes in Brazilian families. Cancer Lett. 2007:245(1-2):96-102.

12. Palmero El, Schüler-Faccini $L$, Caleffi $M$, et al. Detection of $R 337 H$, a germline TP53 mutation predisposing to multiple cancers, in asymptomatic women participating in a breast cancer screening program in southern Brazil. Cancer Lett. 2008:261(1):21-5.

13. Custódio G, Parise GA, Kiesel Filho N, et al. Impact of neonatal screening and surveillance for the TP53 R337H mutation on early detection of childhood adrenocortical tumors. J Clin Oncol. 2013;31(20):2619-26.

14. Masciari S, Van den Abbeele AD, Diller LR, et al. F18-fluorodeoxyglucosepositron emission tomography/computed tomography screening in LiFraumeni syndrome. JAMA. 2008;299:1315-9.

15. Nogueira ST, Lima EN, Nóbrega AF, et al. 18F-FDG PET-CT for surveillance of Brazilian patients with Li-Fraumeni syndrome. Front Oncol. 2015;5:38.

16. Limacher JM, Frebourg T, Natarajan-Ame S, et al. Two metachronous tumors in the radiotherapy fields of a patient with Li-Fraumeni syndrome. Int J Cancer. 2001;96:238-42.

17. Strong LC. General keynote: hereditary cancer: lessons from Li-Fraumeni syndrome. Gynecol Oncol. 2003:88:S4-7. discussion S11-3

18. Bougeard G, Renaux-Petel M, Flaman JM, et al. Revisiting Li-Fraumeni syndrome from TP53 mutation carriers. J Clin Oncol. 2015;33(21):2345-52.

19. Villani A, Tabori U, Schiffman JD, et al. Biochemical and imaging surveillance in germline TP53 mutation carriers with Li-Fraumeni syndrome: a prospective observational study. Lancet Oncol. 2011;12:559-67.

20. Schick F. Whole-body MRI at high field: technical limits and clinical potential. Eur Radiol. 2005;15:946-59.

21. Ladd SC, Ladd ME. Perspectives for preventive screening with total body MRI. Eur Radiol. 2007:17:2889-97.

22. Ladd SC. Whole-body MRI as a screening tool? Eur J Radiol. 2009;70:452-62.

23. Schmidt G, Dinter D, Reiser MF, et al. The uses and limitations of wholebody magnetic resonance imaging. Dtsch Arztebl Int. 2010;107:383-9.

24. Canale S, Vilcot L, Ammari S, et al. Whole body MRI in paediatric oncology. Diagn Interv Imaging. 2014;95:541-50.

25. National Comprehensive Cancer Network. Genetic/familial high-risk assessment: breast and ovarian. Li-Fraumeni syndrome management. NCCN Clinical practice guidelines in oncology; Version 2. 2016. Available at: https:// www.nccn.org/professionals/physician_gls/default.aspx\#genetics_screening. Accessed 18 Apr 2016

26. Anupindi SA, Bedoya MA, Lindell RB, et al. Diagnostic performance of whole-body MRI as a tool for Cancer screening in children with genetic Cancer-predisposing conditions. Am J Roentgenol. 2015:205(2):400-8.

27. Ballinger ML, Best $A$, Mai PL, et al. Baseline surveillance in Li-Fraumeni syndrome using whole-body magnetic resonance imaging: a meta-analysis. JAMA Oncol. 2017;3(12):1634-9.

28. Mai PL, Khincha PP, Loud JT, et al. Prevalence of cancer at baseline screeningin the National Cancer Institute Li-Fraumeni syndrome cohort. JAMA Oncol. 2017:3(12):1640-5.

29. Asdahl PH, Ojha RP, Hasle H. Cancer screening in Li-Fraumeni syndrome [published online August 3, 2017]. JAMA Oncol. https://doi.org/10.1001/ jamaoncol.2017.2459.

30. Gonzalez KD, Noltner KA, Buzin CH, et al. Beyond Li-Fraumeni syndrome: clinical characteristics of families with p53 germline mutations. J Clin Oncol. 2009:27:1250-6. 